\title{
Overproduction, purification,
} (a) CrossMark and characterization of nanosized polyphosphate bodies from Synechococcus sp. PCC 7002

\author{
Fengzheng Gao, Haohao Wu, Mingyong Zeng* ${ }^{*}$, Min Huang and Guangxin Feng
}

\begin{abstract}
Background: Inorganic polyphosphate bodies (PPB) have recently been linked to a variety of functions in mammalian cells. To improve the yield of PPB from Synechococcus sp. PCC 7002 and characterize its form, in this study, a recombinant plasmid containing a polyphosphate kinase ( $p p k$ ) gene was generated and transformed into Synechococcus sp. PCC 7002.

Results: PPB separated by Sephadex G-100 was characterized and added to polarized human intestinal epithelial (Caco-2) cells, and the absorption effect was assessed. The ppk gene was stably expressed by induction with $1 \mu \mathrm{M}$ nickel, and the resulting PPB yield from Synechococcus sp. PCC 7002 cells increased by 89.66\%. Transmission electron microscopy and dynamic light scattering analyses showed that PPB from these cells were nanosized, ranging from a few to approximately 100 nanometres in diameter. PPB can be taken up by Caco- 2 cells and are mainly distributed around lipid droplets.
\end{abstract}

Conclusions: We determined that PPB can be overproduced in Synechococcus sp. PCC 7002 and that the resulting PPB were well absorbed by Caco-2 cells. Microalgae provide a promising "cell factory" for PPB production.

Keywords: Polyphosphate bodies, Polyphosphate kinase gene, Synechococcus sp. PCC 7002, Human intestinal epithelial cells, Lipid droplets

\section{Background}

Most microorganisms, including microalgae [1, 2], have several acclimation strategies to deal with phosphorus limitation and are able to store phosphorus when it is available in excess [3-6]. Inorganic polyphosphate (polyP) is a linear polymer composed of three to several hundred phosphate groups that is found ubiquitously [7]. PolyP plays an important role in supplying raw material for DNA synthesis during the cell division cycle and plays roles in nitrogen fixation and nutrition storage $[8,9]$. PPB (also known as volutin granules) are mineralized structures present in many cells and contain large amounts of

*Correspondence: mingyz@ouc.edu.cn

College of Food Science and Engineering, Ocean University of China, 5

Yushan Road, Qingdao 266003, Shandong, China
polyP [10]. Many cells can accumulate PPB, which can then function as a source of phosphate for the synthesis of nucleic acids and phospholipids or be used for ATP synthesis $[11,12]$.

Mineral nanoparticles have unique advantages in nutrition intervention $[13,14]$. Unlike the short-chain polyP used in the food industry, microorganisms synthesize polyP can be hardly processed by alkaline phosphatase in mammalian intestines [15], so that it can be absorbed by the intestinal epithelial cells with endocytosis [16]. PPB play a probiotic role in protecting intestinal tissue from oxidative damage, inflammation, fibrosis and cancerous lesions $[17,18]$. As a carrier of mineral elements [19], such as calcium [20], iron [21] and zinc [22], it is possible to develop PPB as a new mineral nutrition enhancer; 
however, there are no relevant reports on this subject at present.

PPB have been reported to have an important function during the regreening process of several microalgae, including Anabaena torulosa [23], Chlorella vulgaris [24] and Synechococcus 7942. Synechococcus is one of the main groups of marine cyanobacteria and it plays an important role in the food chain and carbon cycle [25]. Synechococcus sp. PCC 7002 has long been a model organism, alongside Synechocystis sp. PCC 6803 and Synechococcus elongatus PCC 7942, in studies aimed at understanding photosynthetic prokaryotes [26]. As a naturally transformable organism with a sequenced genome, the strain is an excellent platform for genetic engineering in which many foreign genes have been successfully expressed [27-29]. PPB from Synechococcus sp. PCC 7002 are nanosized and much smaller than the PPB obtained from other biological sources and may have special biological activities due to their smaller size and marine origin. However, the ability to obtain high yield of these PPB is one of the main restricting factors for their application. One of the most efficient way to lower the cost for microalgae application is yield improving [30]. The $p p k$ gene is widely found in many bacteria and plays an important role in the production of polyP $[7,31$, 32]. Overexpression of the $p p k$ gene is an efficient way to increase the yield of PPB via the overproduction of polyP [33]. Transmission electron microscopy (TEM) is usually used to observe the appearance of PPB in cells, and the level of PPB can be determined by 4',6-diamidino-2-phenylindole (DAPI) quantification [34, 35].

Synechococcus sp. PCC 7002 is an excellent "cell factory" for PPB production by overexpression of the $p p k$ gene. The goal of this study was to improve the yield of PPB from Synechococcus sp. PCC 7002 through construction and transformation of a plasmid expressing $p p k$ gene into this strain. In addition, we purified and characterized PPB from the engineered Synechococcus sp. PCC 7002 and observed their absorption efficiency in Caco-2 cells, with the expectation of PPB having future applications in human health. This study not only is vital for the development of novel nanosized functional particles but also provides a novel method to utilize marine microalgae resources.

\section{Methods}

\section{Materials}

The Synechococcus sp. PCC 7002 strain used in this study was kindly provided by Prof. Jindong Zhao from the Institute of Hydrobiology, Chinese Academy of Sciences, and was cultured in Medium A [36] at $32{ }^{\circ} \mathrm{C}$ under a light intensity of $100 \mu \mathrm{mol} / \mathrm{m}^{2} \mathrm{~s}$. The pSyn_1 vector (3780 bp) and One Shot ${ }^{\circledR}$ TOP10 Chemically Competent E. coli were obtained from Invitrogen Corporation. Restriction enzymes (HindIII and KpnI) and T4 DNA Ligase were obtained from New England Biolabs. The pEASY-Blunt Zero Cloning Kit was obtained from TransGen Biotech Co. Ltd. (Beijing, China).

\section{DNA manipulations}

Chromosomal DNA was isolated from Synechococcus sp. PCC 7002 using a Generation Capture Column Kit (QIAGEN). The $p p k$ gene sequence was obtained from the NCBI GenBank database (2157 bp, Accession No.: NC_010475.1). Primer sequences:

\section{ppk forward primer: CCCAAGCTTGAAGGAGAT AAA AAG TATATG TCC TCT GCG; \\ ppk reverse primer: CGGGGTACCCTA ATCCAA GCTGTCCTGGAG.}

Primer pairs were designed to amplify a ribosome binding site (RBS) as well as HindIII and KpnI restriction sites at opposing ends of the polymerase chain reaction (PCR) product. The $p p k$ gene does not naturally include these two restriction sites, ensuring that the gene itself would not be cut during the digestion. We also ensured that the distance between the HindIII and KpnI restriction sites in the pSyn_1 vector was sufficient to allow for digestion. The RBS sequence GAAGGAG [37] was placed after the HindIII restriction site in the forward primer and was strong enough for a maximal level of translation. PCR amplifications were carried out in $50 \mu \mathrm{L}$ reaction mixtures, and the PCR programme used for amplification was as follows: $5 \mathrm{~min}$ at $94{ }^{\circ} \mathrm{C} ; 30 \mathrm{~s}$ at $94{ }^{\circ} \mathrm{C}, 40 \mathrm{~s}$ at $60{ }^{\circ} \mathrm{C}$, $1 \mathrm{~min}$ at $72{ }^{\circ} \mathrm{C}$ for 30 cycles; $10 \mathrm{~min}$ at $72{ }^{\circ} \mathrm{C}$. The PCR products were purified and were observed by polyacrylamide gel electrophoresis (PAGE). The DNA polymerase used in the PCR was an ultra-fidelity enzyme to ensure the correctness of the gene amplification. In this study, the target gene was sequenced after every operation step to ensure the correctness.

\section{Cloning of target gene and plasmid}

To obtain enough of the PCR amplified ppk gene to be digested with restriction enzymes, the purified target gene was cloned into the pEASY-Blunt Zero vector (3956 bp) at $25{ }^{\circ} \mathrm{C}$ for $20 \mathrm{~min}$. The recombinant vector containing the $p p k$ gene was named as $p p k+$ pEASY. The $p p k+\mathrm{pEASY}$ and $\mathrm{pSyn} \_1$ vector were transformed into TOP 10 Chemically Competent E. coli for propagation and maintenance. E. coli transformants containing the $p p k+\mathrm{pEASY}$ vector were selected on LB plates with $100 \mu \mathrm{g} / \mathrm{mL}$ ampicillin, while strains containing the pSyn_1 vector were selected for with $100 \mu \mathrm{g} / \mathrm{mL}$ 
spectinomycin. Single colonies containing the target vectors were cultured in liquid LB medium for approximately $10 \mathrm{~h}$. Plasmids were extracted and purified from E. coli using general methods.

\section{Plasmid construction}

The $p p k+\mathrm{pEASY}$ and $\mathrm{pSyn} \_1$ vectors were digested with HindIII and KpnI restriction enzymes to generate linear DNA fragments with compatible cohesive ends. The digestion products were observed by PAGE. The digested target gene and pSyn_1 vector were recovered and purified. The purified $p p k$ insert $(1.5 \mu \mathrm{g})$ and $\mathrm{pSyn} \_1$ vector $(150 \mathrm{ng})$ were ligated together using T4 DNA ligase at $16{ }^{\circ} \mathrm{C}$ for $60 \mathrm{~min}$ in the provided reaction buffer [50 mM Tris- $\mathrm{HCl}$ (pH 7.5), $10 \mathrm{mM} \mathrm{MgCl}, 10 \mathrm{mM}$ DTT, $1 \mathrm{mM}$ ATP]. The ligation time was extended appropriately if the ligation efficiency was low. The T4 DNA ligase was deactivated at $65^{\circ} \mathrm{C}$ for $10 \mathrm{~min}$, and then the ligated products were transformed into TOP10 Chemically Competent $E$. coli. The transformants were selected on LB plates containing $100 \mu \mathrm{g} / \mathrm{mL}$ spectinomycin. The target strain was confirmed to contain the $p p k+\mathrm{pSyn} \_1$ vector by singlecolony PCR. Single colonies selected from the plates were cultured in LB liquid medium. To test the correctness of the constructs, extracted and purified plasmids were digested with either HindIII or KpnI restriction enzyme or were double digested with both enzymes. The plasmid and digested linear DNA fragments were observed by PAGE. The constructed plasmid was transformed into the TOP 10 E. coli strain for propagation and maintenance.

\section{Transformation of Synechococcus sp. PCC 7002}

A total of $1.5 \mathrm{~mL}$ of Synechococcus sp. PCC $7002\left(\mathrm{OD}_{750}\right.$ of 1-2) was harvested by centrifugation at $18,630 \mathrm{~g}$ for $3 \mathrm{~min}$ at room temperature. The supernatant was removed by pipetting, and the cells were resuspended in $1 \mathrm{~mL}$ of fresh medium A by gently pipetting up and down. The cells were centrifuged at $18,630 \mathrm{~g}$ for $1 \mathrm{~min}$ at room temperature and suspended with $100 \mu \mathrm{L}$ of fresh medium A after the supernatant was removed by pipetting. As Synechococcus sp. PCC 7002 is competent, exogenous plasmids can be transformed into cells under natural culture conditions. A total of 100 ng of $p p k+$ pSyn_1 plasmid DNA was added into the suspended cells. After $24 \mathrm{~h}$ of cultivation with weak light, Synechococcus sp. PCC 7002 transformants were selected for on medium A plates for 5-7 days with $10 \mu \mathrm{g} / \mathrm{mL}$ spectinomycin. A selected single colony was passaged several times to test of expression stability and was then cultured in $250 \mathrm{~mL}$ flasks for plasmid extraction. The purified plasmids extracted from ppk-type strains of Synechococcus sp. PCC 7002 were used as a template for PCR using the ppk primers and were sequenced by The Beijing Genomics Institute.

\section{Nickel induction and polyP measurements}

The neutral site vector pSyn_1 has a nickel activated promoter from S. elongatus PCC 6803. Expression was tested using $0.5,1,2$, or $5 \mu \mathrm{M} \mathrm{Ni}^{2+}$ (in the form of nickel nitrate) added to Medium A. A culture treated without nickel was used as a control. All groups in this experiment had the same inoculation concentration and culture time. $O D_{750}$ was measured every day to reflect the growth rate difference of cultures with different concentrations of $\mathrm{Ni}^{2+}$. PPB were extracted from Synechococcus sp. PCC 7002 by water boiling bath for 10 min with HEPES buffer (20 mM HEPES pH 7.0, $150 \mathrm{mM} \mathrm{KCl).} \mathrm{Liquid} \mathrm{superna-}$ tant was obtained by centrifugation at $18,630 \mathrm{~g}$ for $10 \mathrm{~min}$ at room temperature. PolyP has fluorescence at $550 \mathrm{~nm}$ with DAPI without prior purification and occurs almost without interference from DNA, RNA and ADP. The fluorescence intensity can reflect the PolyP quantification [34].

Fluorescence measurements were performed using a HITACHI F-4600 Fluorescence Spectrofluorometer at an excitation wavelength of $415 \mathrm{~nm}$, electric tension of $700 \mathrm{~V}$ and emission wavelength of $550 \mathrm{~nm}$. The excitation bandwidth was $5 \mathrm{~nm}$, and the emission bandwidth was $10 \mathrm{~nm}$. Supernatant samples $(500 \mu \mathrm{L})$ were prepared in microcentrifuge tubes with HEPES buffer and stained with $60 \mu \mathrm{L}$ of $100 \mu \mathrm{M}$ DAPI; they were then vortexed for $5 \mathrm{~s}$, incubated for at least $7 \mathrm{~min}$, vortexed again, and then measured in a final volume of $3 \mathrm{~mL}$ of HEPES buffer in a quartz fluorescence cuvette.

\section{PPB purification and characterization}

The supernatant of Synechococcus sp. PCC 7002 obtained from $10 \mathrm{~min}$ boiling was centrifuged [34], concentrated and filtered through $0.22-\mu \mathrm{m}$ cellulose acetate filter before separation. Filtered supernatant was added to a Sephadex G-100 chromatography column and was eluted with ultrapure water at a $0.5 \mathrm{~mL} / \mathrm{min}$ flow rate. An aliquot from every corresponding peak was collected and detected with DAPI. The separated samples were concentrated and observed by SDS-PAGE for separation effect analysis. The separated sample with high DAPI fluorescence was filtered through $0.22-\mu \mathrm{m}$ cellulose acetate filter and observed using TEM and dynamic light scattering (DLS).

A total of $1 \mathrm{~mL}$ of wild-type and ppk-type Synechococcus sp. PCC 7002 cells were harvested by centrifugation at $9500 \mathrm{~g}$ for $1 \mathrm{~min}$ at room temperature. The cells were cleaned with medium A and normal saline and then were centrifuged at $9500 \mathrm{~g}$ for $1 \mathrm{~min}$. For conventional electron microscopy, collected cells were fixated with $2.5 \%$ glutaraldehyde in $0.1 \mathrm{M}$ phosphate buffer solution (PBS, $\mathrm{pH}$ 7.4) for $2 \mathrm{~h}$ at room temperature and in a $4{ }^{\circ} \mathrm{C}$ refrigerator overnight. After glutaraldehyde fixation, the cells were 
cleaned with PBS for three times for 15 min respectively. The cleaned cells were post-fixed in $1 \% \mathrm{OsO}_{4}$ for $1-1.5 \mathrm{~h}$ and then were cleaned again as method mentioned above. The cells were dehydrated with 50, 70 and 90\% acetone respectively for $15 \mathrm{~min}$, and finally dehydrated with $100 \%$ acetone for $20 \mathrm{~min}$ for three times. Epon-812 was utilized for resin embedment (100\% acetone: embedment solution $2: 1$ for $30 \mathrm{~min} ; 100 \%$ acetone: embedment solution $1: 2$ for $1.5 \mathrm{~h}$ at $37^{\circ} \mathrm{C}$; embedment solution for $2-3 \mathrm{~h}$ at $37^{\circ} \mathrm{C}$ ). The cells were solidified for $24 \mathrm{~h}$ at 37,45 and $60{ }^{\circ} \mathrm{C}$ respectively. The ultrathin sections were provided by Reichert-Jung Ultracut $\mathrm{E}$ ultramicrotome with thick of $70 \mathrm{~nm}$. After staining with uranyl acetate for $15 \mathrm{~min}$ and lead citrate for $10 \mathrm{~min}$, sections were observed with a JEM1200 TEM. The sample used for DLS was added to the formvar stabilized with carbon support films and observed by TEM also.

\section{Cellular uptake experiment}

The polarized Caco- 2 cell model is frequently used to simulate human intestinal absorption [38]. Caco-2 cells were obtained from the Cell Bank of the Chinese Academy of Sciences (Shanghai, China) and seeded at a density of $5 \times 10^{4}$ cells $/ \mathrm{cm}^{2}$ in collagen-treated 24-well plates (BD Biosciences, San Jose, CA, USA). The differentiated cells were gained according to previous method [38] and were cultured in serum-free minimum essential medium (MEM) supplemented with $4 \mathrm{mg} / \mathrm{L}$ hydrocortisone, $5 \mu \mathrm{g} / \mathrm{L}$ selenium, $5 \mathrm{mg} / \mathrm{L}$ insulin, $34 \mu \mathrm{g} / \mathrm{L}$ triiodothyronine, and $20 \mu \mathrm{g} / \mathrm{L}$ epidermal growth factor for $24 \mathrm{~h}$. A total of $10 \mu \mathrm{g} / \mathrm{mL}$ PPB (final concentration) was added to the MEM cell culture. After 30 min of treatment, Caco-2 cells were washed twice with PBS (10 mM, pH 7.4) and then fixed with $2.5 \%$ glutaraldehyde. The ultrathin sections were prepared as the method mentioned above, however the centrifugation parameter should be $800 g$ for $10 \mathrm{~min}$ for Caco- 2 cells. The sections were observed by TEM. Normal cells without PPB treatment were also prepared as ultrathin sections and observed by TEM.

\section{Results}

\section{Objective gene cloning and purification}

The isolated chromosomal DNA from Synechococcus sp. PCC 7002 was cloned using ppk primers by PCR and the PCR products were observed by PAGE. As shown in Fig. 1A, the target gene (2157 bp) obtained by PCR was slightly larger than $2000 \mathrm{bp}$ on the gel. The $p p k$ gene was amplified with a RBS, as well as the restriction enzyme cutting sites HindIII and KpnI at either end. Faint nonspecific bands and primer dimers bands can be seen on the gel. The primers were somewhat long because of the RBS and restriction enzyme cutting sites, which likely increased the possibility non-specific amplification products. To obtain the purified target gene, the PCR products were purified and can be observed clearly in Fig. 1B without interfering bands. The purified target gene was sequenced by Beijing Genomics Institute and was confirmed as the ppk gene of Synechococcus sp. PCC 7002 without mutation, which is important to the success of the study.

\section{Objective gene and vector propagation}

To reveal the same enzyme cutting sites, $p p k+\mathrm{pEASY}$ and pSyn_1 vector extracted from TOP $10 \mathrm{E}$. coli cells were digested with HindIII and KpnI restriction enzymes. The $p p k+$ pEASY vector was verified as lane a in Fig. $1 C$. The electrophoretic band above $6000 \mathrm{bp}$ is concatenated plasmid. Intact supercoiled plasmid is not linear but become so after digestion. Two bands were visible in the $p p k+$ pEASY vector digested sample (lane b) with sizes of approximately $2157 \mathrm{bp}$ (target gene) and $3956 \mathrm{bp}$ (pEASY-Blunt vector), respectively. The pSyn_1 vector was loaded in lane c, and the pSyn_1 vector was digested into two bands with the same restriction enzymes. The smaller band ( $<30 \mathrm{bp}$ ) was too short to be seen on the agarose gel. We can only observe the long band in lane $\mathrm{d}$, which is approximately $3780 \mathrm{bp}$. The target gene band (2157 bp in lane b) and the pSyn_1 vector in lane $d$ were purified for ligation.

\section{Construction of recombinant plasmid and transformants selection}

We observed the $p p k+$ pSyn_1 plasmid in the gel as lane a in Fig. 1D. Concatenated plasmids can also be observed on the gel. To test the correctness of $p p k+\mathrm{pSyn} \_1$ vector, the vector was single digested with either the HindIII or $K p n I$ restriction enzyme. The linear plasmid obtained after digestion was approximately 6000 bp (3780 bp pSyn_1 vector plus 2157 bp ppk gene) as seen in lane b. The $p p k+\mathrm{pSyn} \_1$ vector was also digested with both restriction enzymes, producing two bands with sizes of approximately 4000 and $2000 \mathrm{bp}$, corresponding to the 3780 bp pSyn_1 vector and 2157 bp ppk gene, respectively. The experimental results show that the recombinant $p p k+\mathrm{pSyn} \_1$ vector was successfully built. The $p p k+$ pSyn_1 vector was used to transform Synechococcus sp. PCC 7002. We obtained Synechococcus sp. PCC 7002 transformants with stable expression of the spectinomycin resistance gene, which exhibited stable expression for at least 12 months. Plasmids extracted from Synechococcus sp. PCC 7002 were PCR amplified using the ppk primers. The PCR products were approximately $2157 \mathrm{bp}$ on an agarose gel (Fig. 1E, lane a, b) and were confirmed as the ppk gene of Synechococcus sp. PCC 7002. 

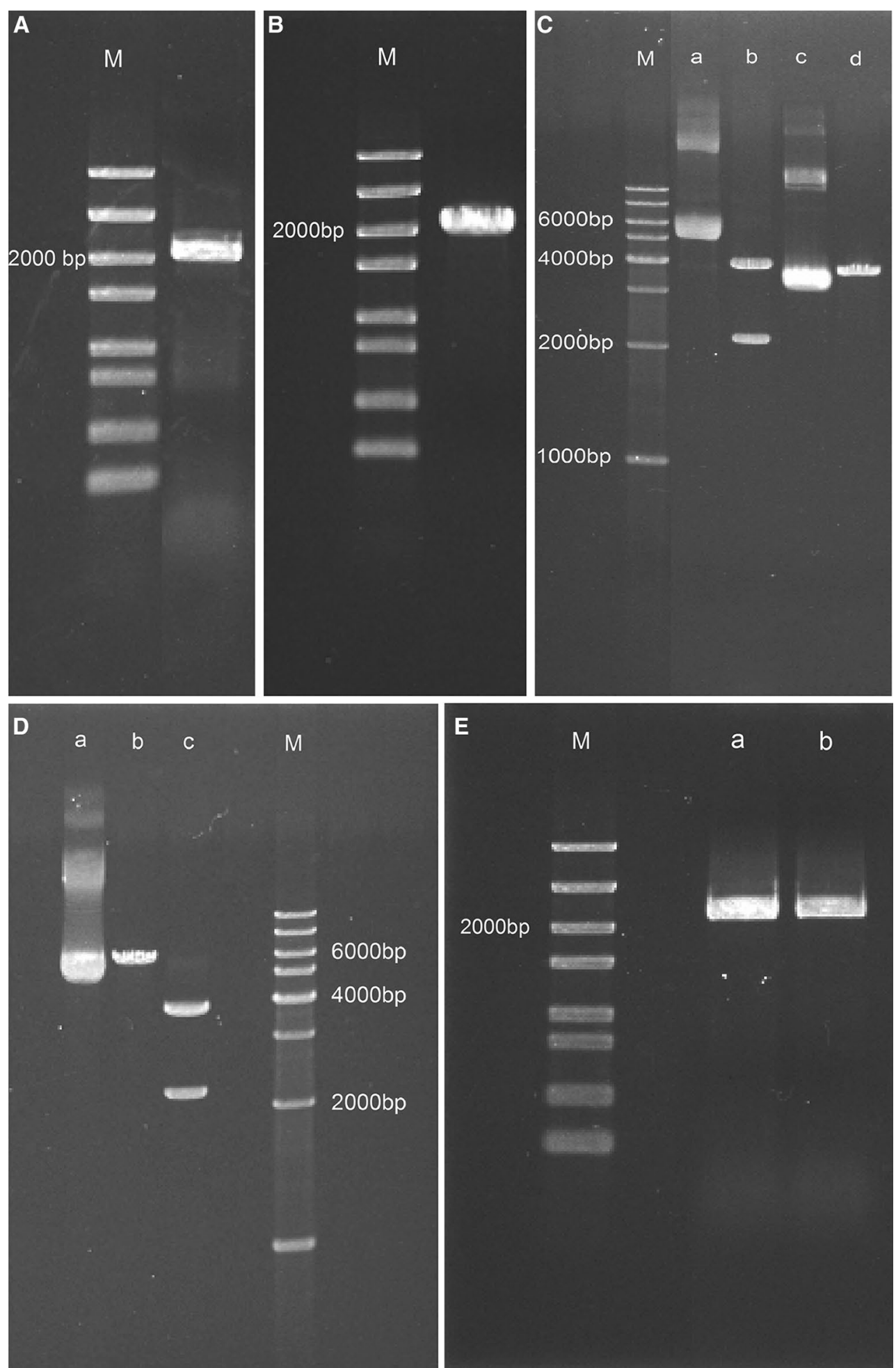

Fig. 1 Electrophoresis results of the construction of transgenic strains on a 1\% agarose gel. A PCR products of target gene; $\mathbf{B}$ purified target gene from PCR products; $\mathbf{C}$ lane a: $p p k+p E A S Y-B l u n t$ vector; line b: $p p k+p E A S Y-B l u n t$ vector digested with Hindlll and Kpnl restriction enzymes; line c: pSyn_1 vector; line d: pSyn_1 vector digested with HindllI and Kpnl restriction enzymes; $\mathbf{D}$ lane a: ppk+pSyn_1 vector; line b: ppk+pSyn_1 vector digested with Hindlll or Kpnl restriction enzymes; line c: ppk+pSyn_1 vector digested with Hindlll and Kpnl restriction enzymes; E PCR products from ppk-type strain plasmid (lane a and b); M in A, B, E was 5 Kb DNA Marker, in C, D was 1 Kb DNA Ladder 


\section{Nickel induction and polyP measurements}

The concentration of nickel in culture medium can affect the yield of PPB because of the nickel promoter [39]. The growth curves of different cultures with different concentration of $\mathrm{Ni}^{2+}$ are shown as Fig. 2A. There is no significant difference in the growth rate between the ppk-type strain cultivated with $0,0.5,1,2 \mu \mathrm{M} \mathrm{Ni}^{2+}$ as well as the wild-type strain cultivated without $\mathrm{Ni}^{2+}$. However, $5 \mu \mathrm{M}$ nickel did not help the cell viability, which indicated toxicity of $\mathrm{Ni}^{2+}$ itself. This result was similar with Chen's report that $2 \mu \mathrm{M} \mathrm{Ni}^{2+}$ did not help the cell viability of the engineering S. elongatus PCC7942 [37], while the ppktype cells in this study had a better tolerance with $2 \mu \mathrm{M}$ nickel.

Fluorescence intensity with different concentrations of nickel treatment is shown in Fig. 2B. The fluorescence intensity of $p p k$-type cells is significantly higher
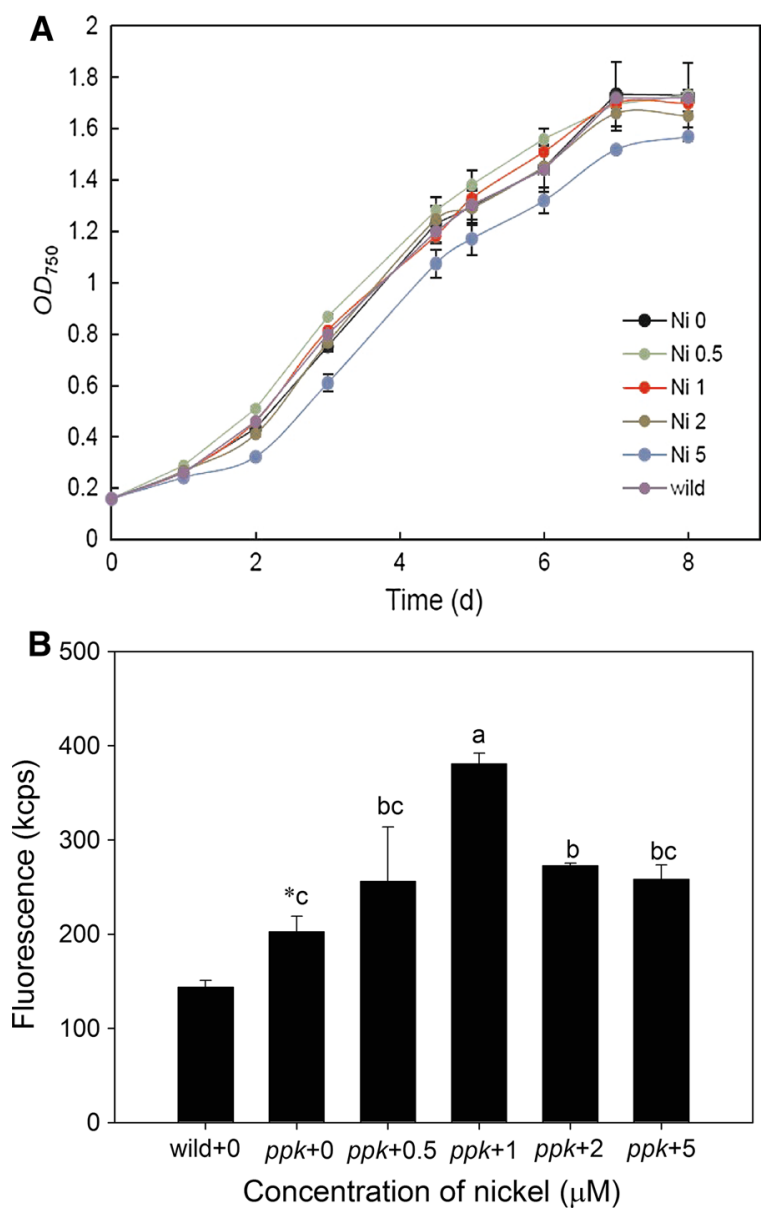

Fig. 2 Growth curves and fluorescence intensity of the wild strain and ppk-type strain. A Growth curves of different cultures of different concentration of $\mathrm{Ni}^{2+} ; \mathbf{B}$ fluorescence intensity with different concentrations of nickel. Same letters above error bars indicate homogeneous subsets; ${ }^{*}$ indicates significant difference $(p<0.05)$ between wild-0 group and ppk-0 group than that of wild-type. In the no-nickel treatment, the fluorescence intensity of the ppk-type strain is $40.94 \%$ higher than that of wild-type. The fluorescence intensity increased as the nickel concentration increased but decreased when the concentration of nickel rose above $1 \mu \mathrm{M}$. The fluorescence intensity was highest with a treatment of $1 \mu \mathrm{M}$ nickel, $89.66 \%$ higher than the wild-type strain and $34.57 \%$ higher than the ppk-type strain without nickel treatment. An appropriate concentration of nickel can thus induce the expression of the $p p k$ gene and then promote the expression of polyP. The result of the overexpression of polyP is the excessive accumulation of PPB. The ppk-type Synechococcus sp. PCC 7002 strain can produce much more PPB than the wild-type strain because of the overexpression of the $p p k$ gene. The result obtained from this research was similar to the result obtained by Chen [37] who observed that 0.5 and $1 \mu \mathrm{M}$ nickel can improve the cadmium tolerance of $S$. elongatus PCC7942 by ppk gene induction.

\section{PPB purification}

PPB from centrifugal supernatant (obtained from $10 \mathrm{~min}$ boiling) were separated by Sephadex G-100. The column chromatographic spectrum diagram is shown in Fig. 3A, in which two separated peaks can be observed. The molecular weight of PPB is much larger than that of impurities; thus, the elution speed must be faster than that of other impurities and is very helpful for PPB separation. The sample with the higher DAPI fluorescence from peak 1 in Fig. 3A was PPB, while the other peak was a mixture of compounds (including Synechococcus sp. PCC 7002 proteins) with a very low level of DAPI fluorescence.

Filtered supernatant without purification and samples from each separated peak were observed by SDSPAGE as shown in Fig. 3B. Several protein bands can be observed in lane a (sample before separation) and lane c (sample from peak 2), while no obvious bands were observed in lane b (sample from peak 1) suggesting the proteins and PPB were separated by Sephadex G-100 effectively. The main proteins (in lane a, c), molecular weight ranging from $11 \mathrm{KD}$ to $17 \mathrm{KD}$, was phycocyanin. The products separated by this method contains a mixture of PPB of different sizes. The PPB separation method using Sephadex G-100 is very simple and convenient. Further purification steps such as ultrafiltration and highperformance liquid chromatography would be needed to obtain PPB with different molecular weights. PPB collected from peak 1 were analysed by DLS and TEM.

\section{TEM observation and DLS analysis}

The wild-type and ppk-type Synechococcus sp. PCC 7002 cells were observed by TEM to clearly observe cellular 

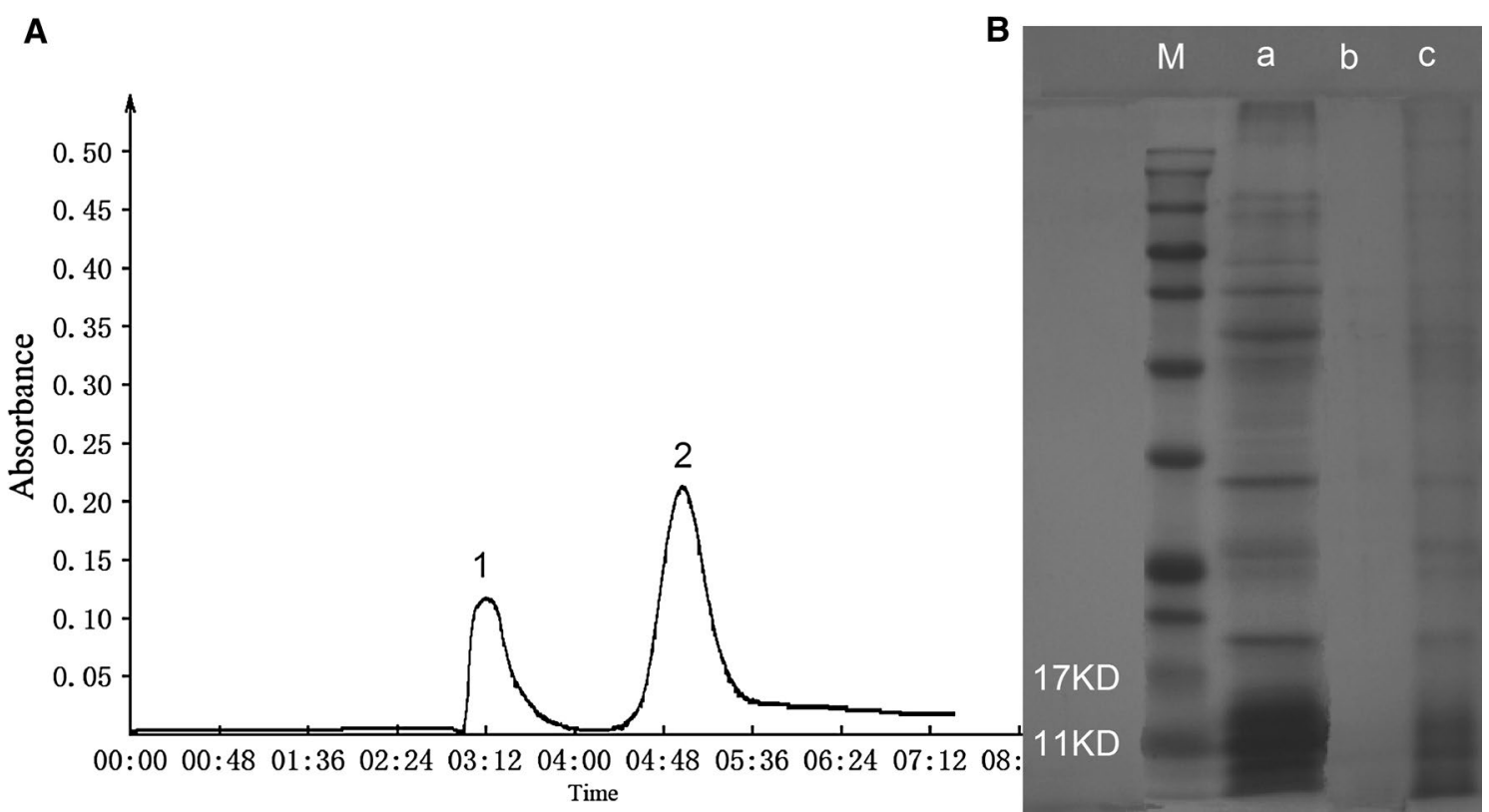

Fig. 3 Sephadex G-100 column chromatography of liquid supernatant and SDS-PAGE observation. A Sephadex G-100 column chromatography; B SDS-PAGE observation; lane a: sample before separation; lane b: sample from peak 1; lane c: sample from peak 2; lane M: marker

structures. Because the PPB contained abundant inorganic metal elements, they appeared as clearly observable black spots (Fig. 4). The number of PPB in ppk-type cells (Fig. 4b) was much greater than that in the wild-type cells (Fig. 4a). We observed less than 5 PPB in the wildtype cells, while that number was approximately 10 in $p p k$-type cells. This result is in line with the DAPI fluorescence intensity experiment. The number of PPB doubled using the genetic modification approach. The yield of PPB also improved significantly, again indicating that the genetic modification was very successful and likely represents one of the most efficient ways to improve the yield of PPB.

The purified PPB were analysed by DLS and TEM. Figure 5a shows the peaks at 14 and $40 \mathrm{~nm}$ that were observed for PPB. The size of PPB ranged from a few to one hundred nanometres and was consistent with the TEM results, though few were larger than $100 \mathrm{~nm}$. In recent years, nanosized materials have become a research hot spot for researchers all around the world. Nanosized PPB from Synechococcus sp. PCC 7002 are a new functional material, and the nanosized form improves the application potential for PPB.

The sample analysed by DLS was also observed by TEM. As shown in Fig. 5b, we can clearly see nanosized PPB with different sizes on the photograph. The sizes of almost all the PPB were below $100 \mathrm{~nm}$. The TEM result was consistent with DLS analysis. This result also indicated that PPB kept a good sized form during the boiling extraction process, demonstrating that the thermal stability of PPB is good since they were stable after $10 \mathrm{~min}$ of boiling. This characteristic will aid in its further application. The purified PPB were stored at $-20^{\circ} \mathrm{C}$.

\section{Cellular uptake experiment}

Many studies have shown that PPB are a functional part of cellular metabolism since they provide materials for cells. Caco-2 cells were prepared in ultrathin sections after cultivation with $10 \mu \mathrm{g} / \mathrm{mL}$ PPB for $30 \mathrm{~min}$. Cell sections without staining were observed by TEM as shown in Fig. 6. Black material with high contrast are PPB while other organic substances can't be observed without staining. The intestinal villi can be seen on Caco-2 cells in Fig. 6a, indicating the success of the epithelial cell model construction. Black irregular fragments of PPB seen in Fig. 6b can be observed in lysosomes. However, only some debris was observed, and whole PPB were not observed in the cell interior. The possible reason for this phenomenon was that the PPB treatment time was a bit long. The capture of whole PPB form in cells is particularly difficult since $\mathrm{PPB}$ can be quickly absorbed and degraded in lysosomes. A lot of lipid droplets were observed in the cells cultivated with PPB under lower magnification (Fig. 6c). As the basic structure of PPB is polyP, PPB are lipophilic materials containing plenty of phosphate. Perhaps, cells can utilize PPB for their rich phosphate content to produce phospholipids with the result being an increased number of lipid droplets. The 

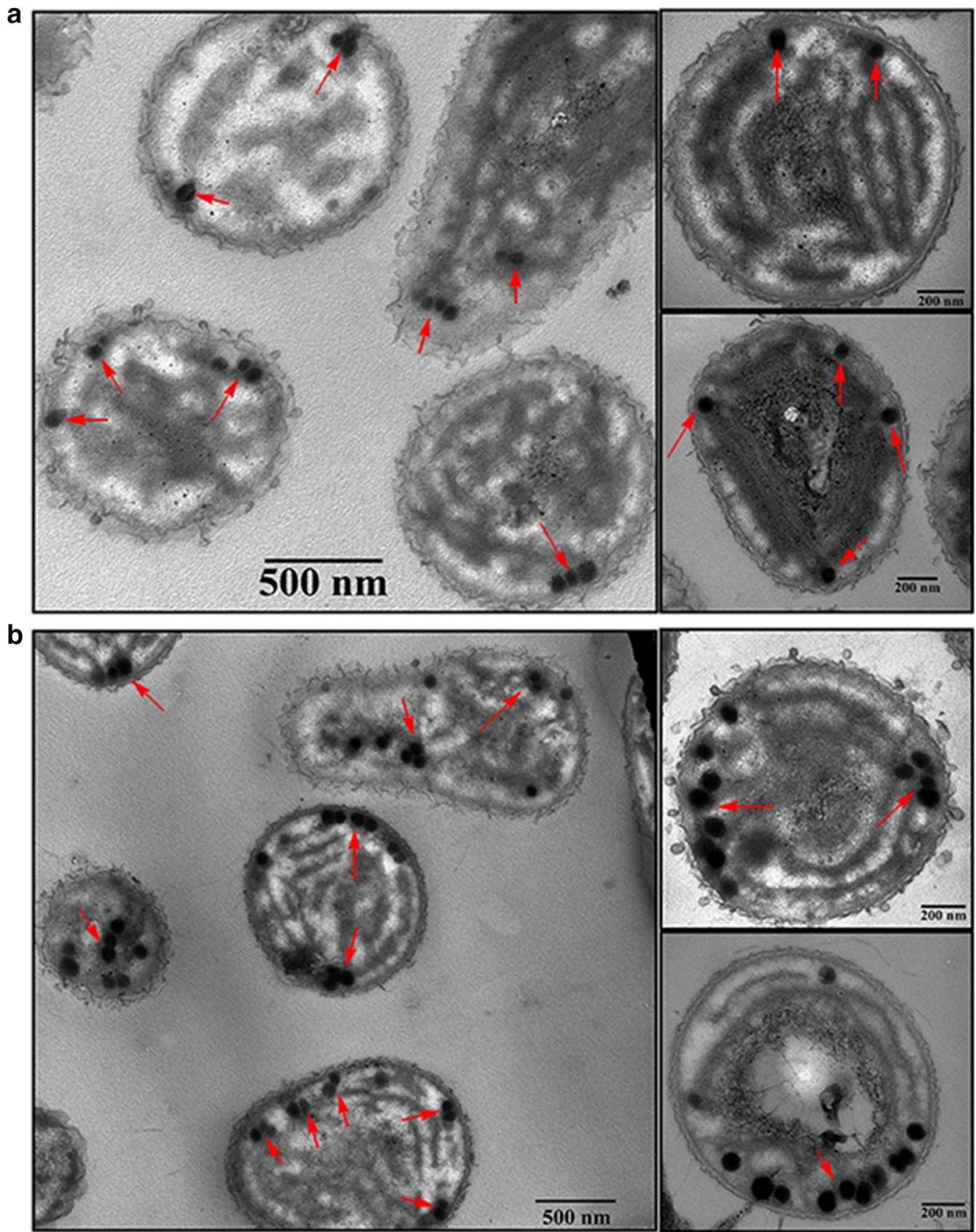

Fig. 4 TEM observation of cells. a Wild-type cells; $\mathbf{b} p p k$-type cells

degraded PPB shown as Fig. 6e are mainly scattered around the edge of lipid droplets in cells, demonstrating that they have a strong lipophilic feature. Meanwhile, as we can see in Fig. 6d, no black debris were found around the lipid droplets in the cells without PPB treatment. On the further enlarged image (Fig. 6f), PPB can be observed very clearly distributed around the lipid droplets.

\section{Discussion}

Here, we obtained almost double the yield of PPB through our transgenic method based on the observed fluorescence intensity. The yield of PPB can be affected by the nutrients in the medium, especially phosphorus. The yield of PPB may be improved further by optimization of culture conditions. The $p p k$ gene studied in this paper, 


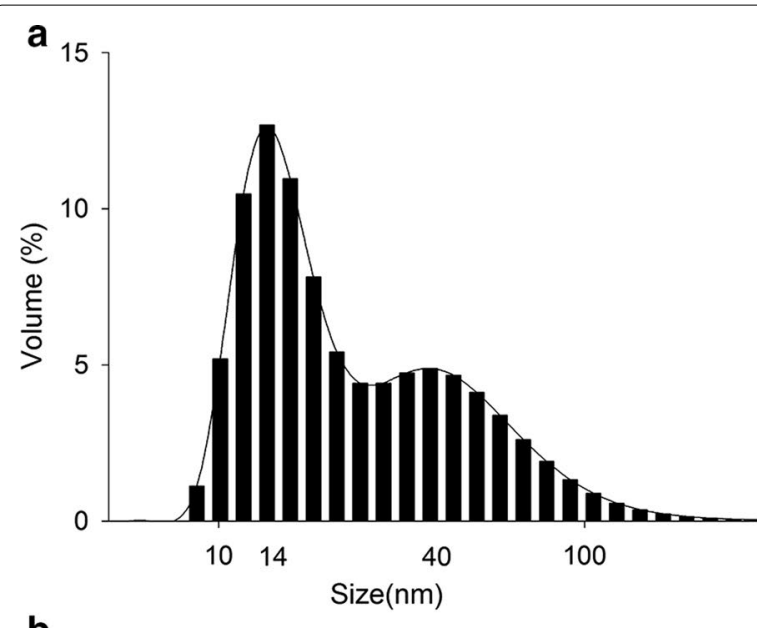

b

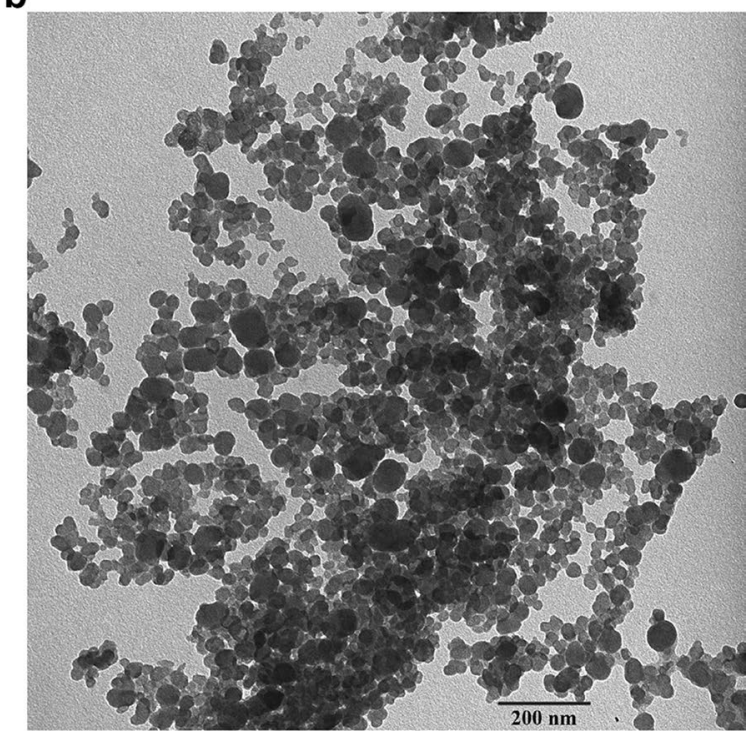

Fig. 5 The DLS and TEM results for purified PPB. a DLS; b TEM

was obtained from Synechococcus sp. PCC 7002; thus, there is no need to worry about the safety of PPB from the ppk-type strain. We concluded that the engineered Synechococcus sp. PCC 7002 is a good "cell factory" for PPB high-efficient production.

From our data, we also concluded that PPB from Synechococcus sp. PCC 7002 are mainly distributed around the cell edge (Fig. 4). Unlike PPB from other Synechococcus, such as Anacystis nidulan (approximately $200 \mathrm{~nm}$ ) [40], thermophilic Synechococcus sp. from microbial mats (approximately 100-300 nm) [2] and S. elongatus PCC 7942 (66.8-245.8 nm) [41], PPB from Synechococcus sp. PCC 7002 were smaller. The sizes of most PPB were below $100 \mathrm{~nm}$ (Fig. 5) and changed with the growth of cells. The PPB may be very small, just a few nanometres, at the beginning phase of cultivation and become larger in the later phases of growth. The PPB are also affected by environmental factors, especially the phosphorus content in medium. It seemed that PPB were much larger when given enough phosphorus than under phosphorus limited conditions [42]. Along with currently known uses, PPB may be developed into a new functionally active substances in the future.

In addition, PPB can be absorbed by Caco- 2 cells effectively (Fig. 6), demonstrating that they can be absorbed in the mammalian intestine. Similarly, Segawa et al. [17] reported that polyP from L. brevis SBC8803 enhanced F-actin stability of human colonic epithelial Caco2/BBE cells and improved intestinal injury and survival rate of mice treated with a lethal dose of DSS. It may be possible that exogenous addition of PPB enhances the function of cells and improves the overall body function. Unlike the research from Segawa et al. [17] and Kashima et al. [18], we studied the absorption of the whole PPB not polyP in Caco- 2 cells. Nanosized PPB without digestion may have better function with mineral elements retained.

In previous research, the overexpression of $\mathrm{PPB}$ improved cell tolerance to heavy metals [43-45] since PPB can help cells to store metal elements such as calcium, iron and zinc. Mineral substances entering cells with PPB may not easy be lost because of the lipophilic features. Thus, PPB may have a good absorption efficiency as a mineral supplement. As microalgae has a strong metal adsorption characteristic [46, 47], we can increase the concentration of mineral elements in culture medium to strengthen its absorbability and subsequently increase the mineral elements content in PPB. This observation provided an innovative idea for nutrient enrichment by biomineralization.

Microorganisms are one of the most attractive and simple sources for the synthesis of different types of metal nanoparticles [48]. Microalgae is rich in nutrition [49, 50], such as pigments, proteins, lipids, carbohydrates, vitamins and anti-oxidants, with applications in cosmetics, nutritional and pharmaceuticals industries [51]. Synechococcus plays an important role in the food cycle in the ocean. Synechococcus is a good source of nutrition, functioning as a primary producer. Marine active substances usually have a better effect than do terrestrial ones [52]. The effective utilization of marine PPB will improve the value of Synechococcus sp. PCC 7002. The yield improvement of PPB makes possible widespread use of PPB, and the specific composition and function of PPB is a question deserving further study.

\section{Conclusion}

In the present study, we genetically engineered a Synechococcus sp. PCC 7002 strain that produced a twofold increase in PPB. The PPB were nanosized and ranged from a few to approximately 100 nanometres in diameter. 

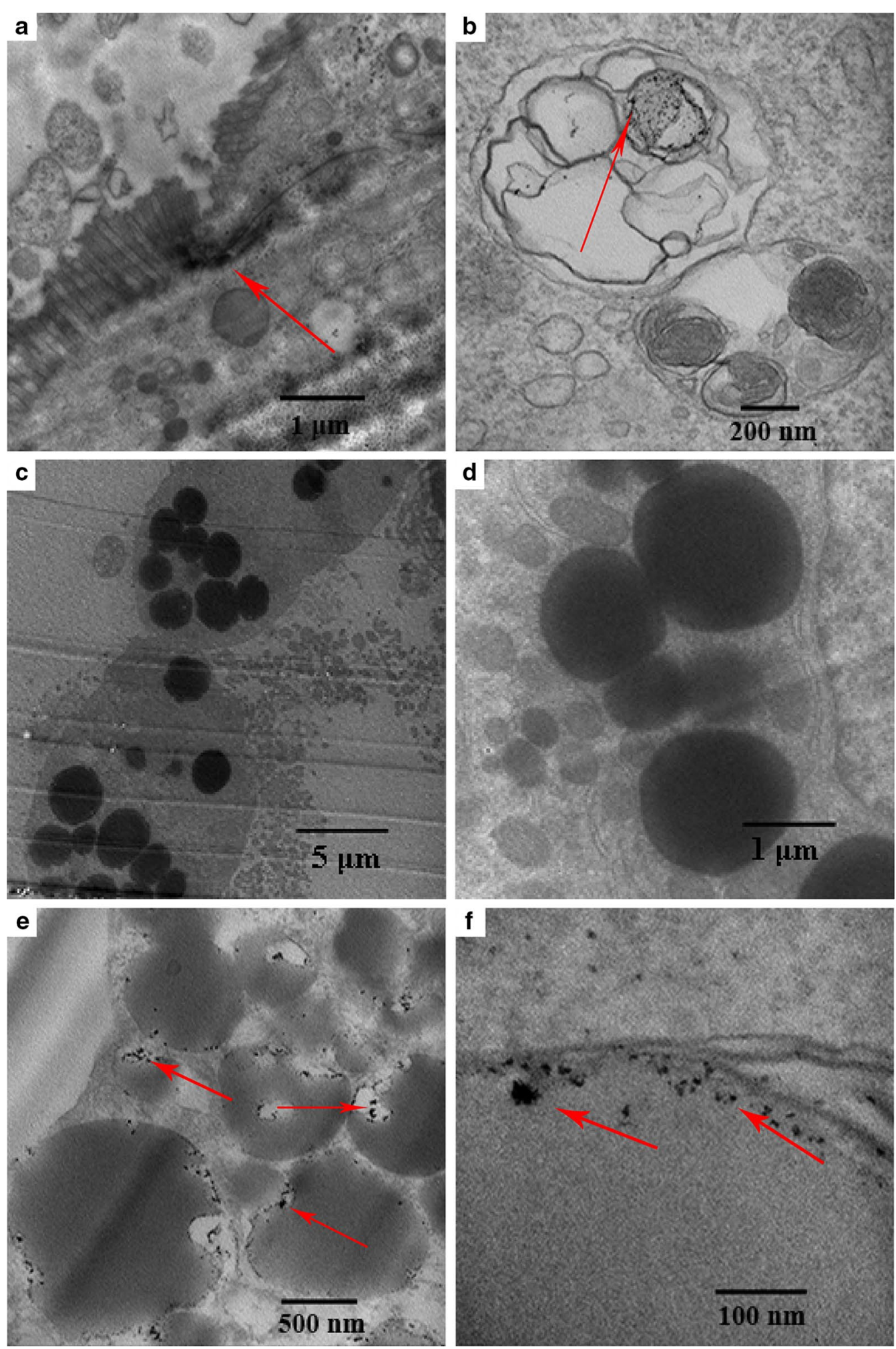

Fig. 6 PPB absorbed by Caco-2 cells under TEM. a Intestinal villi; b lysosome; c lower magnification image of the cells with PPB treatment; $\mathbf{d}$ lipid droplets in the cells without PPB treatment; $\mathbf{e}$ lipid droplets in the cells with PPB treatment; $\mathbf{f}$ further enlarged image of PPB fragments on the edge of lipid droplets 
Moreover, PPB were able to be effectively absorbed by Caco- 2 cells and were predominantly scattered on the edge of lipid droplets. This article provides a promising "cell factory" for PPB production using engineering microalgae.

\section{Abbreviations}

PPB: polyphosphate bodies; TEM: transmission electron microscopy; DLS: dynamic light scattering; DPAI: 4',6-diamidino-2-phenylindole; RBS: ribosome binding site; PCR: polymerase chain reaction; PAGE: polyacrylamide gel electrophoresis; MEM: minimum essential medium.

\section{Authors' contributions}

FZG and MYZ designed the experiments and take responsibility for the integrity of the work as a whole, FZG, HHW, MH and GXF performed the experiments and analysis, and MYZ supervised the research, and FZG wrote the paper. All authors commented on the results and modified the manuscript. All authors read and approved the final manuscript.

\section{Acknowledgements}

We would like to acknowledge Professor Jindong Zhao from the Institute of Hydrobiology, Chinese Academy of Sciences, for his help in wild strain donation. We thank professor Chunxia Dong from Peking University for her help in microalgae cultivation.

\section{Competing interests}

The authors declare that they have no competing interests.

\section{Availability of data and materials}

All data generated or analyzed during this study are included in this published article.

\section{Consent for publication}

Not applicable.

\section{Ethics approval and consent to participate}

Not applicable.

\section{Funding}

This work was supported by the National Natural Science Foundation of China (No. 31601406); the Natural Science Foundation of Shandong Province of China (No. ZR2016CB30); and the Applied Basic Research Project of Qingdao of China (No. 16-5-1-16-jch).

\section{Publisher's Note}

Springer Nature remains neutral with regard to jurisdictional claims in published maps and institutional affiliations.

Received: 23 September 2017 Accepted: 5 February 2018 Published online: 20 February 2018

\section{References}

1. Zhu S, Wang Y, Xu J, Shang C, Wang Z, Xu J, Yuan Z. Luxury uptake of phosphorus changes the accumulation of starch and lipid in Chlorella sp. under nitrogen depletion. Bioresour Technol. 2015;198:165-71.

2. Gomez-Garcia MR, Fazeli F, Grote A, Grossman AR, Bhaya D. Role of polyphosphate in thermophilic Synechococcus sp. from microbial mats. J Bacteriol. 2013;195:3309-19.

3. Watanabe T, Ozaki N, Iwashita K, Fujii T, lefuji H. Breeding of wastewater treatment yeasts that accumulate high concentrations of phosphorus. Appl Microbiol Biotechnol. 2008;80:331-8.

4. Huang W, Huang W, Li H, Lei Z, Zhang Z, Tay JH, Lee DJ. Species and distribution of inorganic and organic phosphorus in enhanced phosphorus removal aerobic granular sludge. Bioresour Technol. 2015;193:549-52.
5. Merchant SS, Helmann JD. Elemental economy: microbial strategies for optimizing growth in the face of nutrient limitation. Adv Microb Physiol. 2012:60:91-210.

6. Hsieh YJ, Wanner BL. Global regulation by the seven-component Pi signaling system. Curr Opin Microbiol. 2010;13:198-203.

7. Brown MR, Kornberg A. The long and short of it_-polyphosphate, PPK and bacterial survival. Trends Biochem Sci. 2008;33:284-90.

8. Seki Y, Nitta K, Kaneko Y. Observation of polyphosphate bodies and DNA during the cell division cycle of Synechococcus elongatus PCC 7942. Plant Biol (Stuttg). 2014;16:258-63.

9. Liberton M, Austin JR 2nd, Berg RH, Pakrasi HB. Unique thylakoid membrane architecture of a unicellular $\mathrm{N}_{2}$-fixing cyanobacterium revealed by electron tomography. Plant Physiol. 2011;155:1656-66.

10. Ruiz FA, Marchesini N, Seufferheld M, Docampo R. The polyphosphate bodies of chlamydomonas reinhardtii possess a proton-pumping pyrophosphatase and are similar to acidocalcisomes. J Biol Chem. 2001;276:46196-203.

11. Albi T, Serrano A. Two strictly polyphosphate-dependent gluco(manno) kinases from diazotrophic Cyanobacteria with potential to phosphorylate hexoses from polyphosphates. Appl Microbiol Biotechnol. 2015;99:3887-900.

12. Allen MM. Cyanobacterial cell inclusions. Annu Rev Microbiol. 1984;38:1-25

13. Hilty FM, Arnold M, Hilbe M, Teleki A, Knijnenburg JT, Ehrensperger F, Hurrell RF, Pratsinis SE, Langhans W, Zimmermann MB. Iron from nanocompounds containing iron and zinc is highly bioavailable in rats without tissue accumulation. Nat Nanotechnol. 2010;5:374-80.

14. Wang $\mathrm{H}$, Zhang J, Yu H. Elemental selenium at nano size possesses lower toxicity without compromising the fundamental effect on selenoenzymes: comparison with selenomethionine in mice. Free Radic Biol Med. 2007:42:1524-33.

15. Dedkova EN, Blatter LA. Role of $\beta$-hydroxybutyrate, its polymer poly- $\beta$ hydroxybutyrate and inorganic polyphosphate in mammalian health and disease. Front Physiol. 2014;5:260.

16. Saiki A, Ishida Y, Segawa S, Hirota R, Nakamura T, Kuroda A. A Lactobacillus mutant capable of accumulating long-chain polyphosphates that enhance intestinal barrier function. Biosci Biotechnol Biochem. 2016;80:955-61.

17. Segawa S, Fujiya M, Konishi H, Ueno N, Kobayashi N, Shigyo T, Kohgo Y. Probiotic-derived polyphosphate enhances the epithelial barrier function and maintains intestinal homeostasis through integrin-p38 MAPK pathway. PLoS ONE. 2011;6:e23278.

18. Kashima S, Fujiya M, Konishi H, Ueno N, Inaba Y, Moriichi K, Tanabe H, Ikuta K, Ohtake T, Kohgo Y. Polyphosphate, an active molecule derived from probiotic Lactobacillus brevis, improves the fibrosis in murine colitis. Transl Res. 2015;166:163-75.

19. Goldberg J, Gonzalez H, Jensen TE, Corpe WA. Quantitative analysis of the elemental composition and the mass of bacterial polyphosphate bodies using STEM EDX. Microbios. 2001;106:177-88.

20. Li Y, Zou J, Zhang L, Sun J. Aerobic granular sludge for simultaneous accumulation of mineral phosphorus and removal of nitrogen via nitrite in wastewater. Bioresour Technol. 2014;154:178-84.

21. Nagasaka S, Yoshimura E. External iron regulates polyphosphate content in the acidophilic, thermophilic alga Cyanidium caldarium. Biol Trace Elem Res. 2008;125:286-9.

22. Andrade L, Keim CN, Farina M, Pfeiffer WC. Zinc detoxification by a cyanobacterium from a metal contaminated bay in Brazil. Braz Arch Biol Technol. 2004;47:147-52.

23. Acharya C, Apte SK. Novel surface associated polyphosphate bodies sequester uranium in the filamentous, marine cyanobacterium, Anabaena torulosa. Metallomics. 2013:5:1595-8.

24. Chu FF, Shen XF, Lam PK, Zeng RJ. Polyphosphate during the regreening of Chlorella vulgaris under nitrogen deficiency. Int J Mol Sci. 2015;16:23355-68.

25. Flombaum P, Gallegos JL, Gordillo RA, Rincón J, Zabala LL, Jiao N, Karl DM Li WK, Lomas MW, Veneziano D, Vera CS, Vrugt JA, Martiny AC. Present and future global distributions of the marine Cyanobacteria Prochlorococcus and Synechococcus. Proc Natl Acad Sci USA. 2013;110:9824-9.

26. Hendry JI, Prasannan CB, Joshi A, Dasgupta S, Wangikar PP. Metabolic model of Synechococcus sp. PCC 7002: prediction of flux distribution and network modification for enhanced biofuel production. Bioresour Technol. 2016:213:190-7. 
27. Ruffing AM, Jensen TJ, Strickland LM. Genetic tools for advancement of Synechococcus sp. PCC 7002 as a cyanobacterial chassis. Microb Cell Fact. 2016;15:190.

28. Davies FK, Work VH, Beliaev AS, Posewitz MC. Engineering limonene and bisabolene production in wild type and a glycogen-deficient mutant of Synechococcus sp. PCC 7002. Front Bioeng Biotechnol. 2014;2:21.

29. Work VH, Melnicki MR, Hill EA, Davies FK, Kucek LA, Beliaev AS, Posewitz MC. Lauric acid production in a glycogen-less strain of Synechococcus sp. PCC 7002. Front Bioeng Biotechnol. 2015;3:48.

30. Ruiz J, Olivieri G, de Vree J, Bosma R, Willems P, Reith H, Eppink MHM, Kleinegris DMM, Wijffels RH, Barbosa MJ. Towards industrial products from microalgae. Energy Environ Sci. 2016;9:3036-43.

31. Weerasekara AW, Jenkins S, Abbott LK, Waite I, McGrath JW, Larma I, Eroglu E, O'Donnell A, Whiteley AS. Microbial phylogenetic and functional responses within acidified wastewater communities exhibiting enhanced phosphate uptake. Bioresour Technol. 2016;220:55-61.

32. Rao NN, Gómez-García MR, Kornberg A. Inorganic polyphosphate: essential for growth and survival. Annu Rev Biochem. 2009;78:605-47.

33. Liang M, Frank S, Lünsdorf H, Warren MJ, Prentice MB. Bacterial microcompartment-directed polyphosphate kinase promotes stable polyphosphate accumulation in E. coli. Biotechnol J. 2017. https://doi. org/10.1002/biot.201600415.

34. Martin P, Van Mooy BA. Fluorometric quantification of polyphosphate in environmental plankton samples: extraction protocols, matrix effects, and nucleic acid interference. Appl Environ Microbiol. 2013;79:273-81.

35. Kulakova AN, Hobbs D, Smithen M, Pavlov E, Gilbert JA, Quinn JP, McGrath JW. Direct quantification of inorganic polyphosphate in microbial cells using 4'-6-diamidino-2-phenylindole (DAPI). Environ Sci Technol. 2011;45:7799-803.

36. Ludwig M, Bryant DA. Transcription profiling of the model cyanobacterium Synechococcus sp. strain PCC7002 by NextGen (SOLiD ${ }^{\mathrm{TM}}$ ) sequencing of cDNA. Front Microbiol. 2011;2:41.

37. Wu T, Grassel C, Levine MM, Barry EM. Live attenuated Shigella dysenteriae type 1 vaccine strains overexpressing shiga toxin B subunit. Infect Immun. 2011;79:4912-22.

38. Wu H, Zhu S, Zeng M, Liu Z, Dong S, Zhao Y, Huang H, Lo YM. Enhancement of non-heme iron absorption by anchovy (Engraulis japonicus) muscle protein hydrolysate involves a nanoparticle-mediated mechanism. J Agric Food Chem. 2014;62:8632-9.

39. Chen $X$. Engineering heavy metal resistance in cyanobacteria Synechococcus elongatus PCC7942. Dissertation University of Illinois, UrbanaChampaign. 2013
40. Lawry NH, Jensen TE. Deposition of condensed phosphate as an effect of varying sulfur deficiency in the Cyanobacterium Synechococcus sp. (Anacystis nidulans). Arch Microbiol. 1979;120:1-7.

41. Murata K, Hagiwara S, Kimori Y, Kaneko Y. Ultrastructure of compacted DNA in cyanobacteria by high-voltage cryo-electron tomography. Sci Rep. 2016;6:34934.

42. Jensen TE, Sicko LM. Phosphate metabolism in blue-green algae. I. Fine structure of the "polyphosphate overplus" phenomenon in Plectonema boryanum. Can J Microbiol. 1974;20:1235-9.

43. Keasling JD, Hupf GA. Genetic manipulation of polyphosphate metabolism affects cadmium tolerance in Escherichia coli. Appl Environ Microbiol. 1996;62:743-6.

44. Nagata T, Kimura T, Pan-Hou H. Engineering expression of polyphosphate confers cadmium resistance in tobacco. J Toxicol Sci. 2008:33:371-3.

45. Andreeva N, Ryazanova L, Dmitriev V, Kulakovskaya T, Kulaev I. Cytoplasmic inorganic polyphosphate participates in the heavy metal tolerance of Cryptococcus humicola. Folia Microbiol (Praha). 2014;59:381-9.

46. Mehta SK, Gaur JP. Use of algae for removing heavy metal ions from wastewater: progress and prospects. Crit Rev Biotechnol. 2005;25:113-52.

47. Lee BD, Apel WA, Walton MR. Calcium carbonate formation by Synechococcus sp. strain PCC 8806 and Synechococcus sp. strain PCC 8807. Bioresour Technol. 2006;97:2427-34

48. Salunke BK, Sawant SS, Lee SI, Kim BS. Comparative study of $\mathrm{MnO}_{2}$ nanoparticle synthesis by marine bacterium Saccharophagus degradans and yeast Saccharomyces cerevisiae. Appl Microbiol Biotechnol. 2015;99:5419-27.

49. Postma PR, Suarez-Garcia E, Safi C, Yonathan K, Olivieri G, Barbosa MJ Wijffels RH, Eppink MH. Energy efficient bead milling of microalgae: effect of bead size on disintegration and release of proteins and carbohydrates. Bioresour Technol. 2017;224:670-9.

50. Vanthoor-Koopmans M, Wijffels RH, Barbosa MJ, Eppink MH. Biorefinery of microalgae for food and fuel. Bioresour Technol. 2013;135:142-9.

51. Chew KW, Yap JY, Show PL, Suan NH, Juan JC, Ling TC, Lee DJ, Chang JS. Microalgae biorefinery: high value products perspectives. Bioresour Technol. 2017;229:53-62

52. Romano G, Costantini M, Sansone C, Lauritano C, Ruocco N, lanora A. Marine microorganisms as a promising and sustainable source of bioactive molecules. Mar Environ Res. 2017;128:58-69.

\section{Submit your next manuscript to BioMed Central and we will help you at every step:}

- We accept pre-submission inquiries

- Our selector tool helps you to find the most relevant journal

- We provide round the clock customer support

- Convenient online submission

- Thorough peer review

- Inclusion in PubMed and all major indexing services

- Maximum visibility for your research

Submit your manuscript at www.biomedcentral.com/submit
BioMed Central 